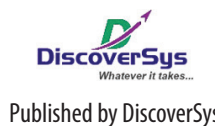

Published by DiscoverSys

\section{Smoking as a health problem: A priority-setting study in a tobacco industry dependent village}

\author{
Nuzulul Kusuma Putri, ${ }^{1,2^{*}}$ Riris Diana Rachmayanti ${ }^{3}$
}

CrossMark

\section{ABSTRACT}

Background and purpose: Indonesia is one of the most cigarettefriendly countries. The tobacco industry has gained economic dependence both nationally and domestically. Baureno Village in Indonesia has more than half of its population relied their life on the tobacco industry for long time. This study analysed how this high tobacco dependent community considered the smoking behaviour as one of prioritized health problems.

Methods: This priority-setting study was conducted in quantitative and qualitative phases sequently. The quantitative data on smoking behaviour were collected on 251 households as the samples. This study captured the twelve healthy family indicators issued by The Indonesia Ministry of Health. Further, this data were brought into two different focus group discussions with community leaders and primary healthcare workers to understand how this community considered smoking as a health problem. Their prespective on prioritized health problem was revealed by performing a prioritysetting analysis.

Results: Smoking behaviour in cigarette producing areas is the impact of the economic dependence created by the tobacco industry. Ease of access and weak supervision of cigarette distribution in producing cigarette region caused smoking behaviour to be common place in this community group. Community considered smoking as a bottom priority of health problems, while health workers considered smoking as the second priority out of four identified health problems.

Conclusion:. Community and health workers have a different prioritized health problems. Education to community should be enhanced to increase their awareness on the health impacts of tobacco smoking.
${ }^{1}$ The Airlangga Centre of Health Policy (ACeHAP)

${ }^{2}$ Department of Health Policy and Administration, Faculty of Public Health, Universitas Airlangga, Surabaya, Indonesia, ${ }^{3}$ Department of Health Promotion and Behavior, Faculty of Public Health, Universitas Airlangga, Surabaya, Indonesia
${ }^{*}$ Correspondence to: Nuzulul Kusuma Putri, The Airlangga Centre of Health Policy (ACeHAP), Department of Health Policy and Administration, Faculty of Public Health, Universitas Airlangga, Surabaya, Indonesia nuzululkusuma@fkm.unair.ac.id

Keywords: priority-setting, smoking behaviour, tobacco industry

Cite This Article: Putri, N.K., Rachmayanti, R.D. 2019. Smoking as a health problem: A priority-setting study in a tobacco industry dependent village. Public Health and Preventive Medicine Archive 7(2): 135-139. D0I:10.15562/phpma.v7i2.217

\section{INTRODUCTION}

Previous studies highlighted how the marketing strategy of tobacco companies influence smoking behaviour. ${ }^{1-3}$ In various place-based smoking behaviour studies, smokers neighbourhood exposure are the most frequently analysed..$^{3-5}$ On the other hand, little is known in the high economic dependence of community living in cigarette-producing areas. High economic dependence should be considered as an important social problem rather than the results of a public policy.

A study conducted in China, the country with the largest number of active smokers in the world, shows that there is a significant difference in the number of smokers between cigarette and non-cigarette producing areas. ${ }^{6}$ This condition indicates a conflict between the goals of economic growth and health quality improvement efforts. The increasing number of companies which producing cigarettes certainly offset their efforts to more widely markets their products. Marketing of cigarette products does not only target the active smokers but also the younger population.

The number of smokers in Indonesia until 2017 has reached one third of its total population. ${ }^{7}$
This figure is likely to continue to grow due to the weak restriction of cigarettes in Indonesia. People in Indonesia can easily get cigarettes in retailers. Marketing the cigarettes through retailers is a widely used strategy which performed by the cigarette industry. ${ }^{8}$ Promotion of cheap prices and a variety of flavours are positioned in retailers to attract the public smoking.

The access will be easier in the areas where the tobacco industry is established. The district economic dependence toward high incomes of cigarettes industry makes the monitoring of cigarette distribution lower. ${ }^{6}$ Self-control of the community to avoid smoking is the only weak barriers in community in cigarette-producing areas. ${ }^{1}$ Therefore, health workers are required to improve community understanding about smoking as a serious health problem.

This study aims to identify the smoking behaviour of population in cigarette producing areas and to analyse differences in perceptions between community and health workers toward smoking behaviour as a health problem. The results of this study are expected to be an evaluation for decision makers in determining the strategy of 
cigarette prevention especially in population with high economic dependence on cigarette industry.

\section{METHODS}

This priority-setting study was conducted in quantitative and qualitative phases sequently. The quantitative approach is a cross sectional descriptive. Quantitative data on smoking behavior were collected by interview on the households in one of the biggest cigarette-producing villages in Bojonegoro District. The population in this villages mostly work in the tobacco modern factory that operated in the village. Bojonegoro is one of districts in East Java Province with large tobacco industries. The Industry and Labour Office of Bojonegoro revealed that at least $50 \%$ of their workforce works on tobacco warehouses and other tobacco industry in 2016. This number is still outside of high number of tobacco farmers in Bojonegoro. In the village where this study performed, there are several cigarette factories which have been established. These cigarette industries are not only covered by modern cigarette industry but also the traditional one. Due to this high probability of employment, majority of its population choose the cigarette industry as their main livelihood. Simple random sampling was conducted to select 251 households that became the study samples.

Qualitative data on the perception of community and health workers regarding smoking behaviour as a health problem were analysed by performing problem priority setting analysis. First, we conducted a focus group discussion with the community represented by the community leaders and the health cadres in the village. Before we started the focus group discussion, we presented the measurement results of twelve indicators of Indonesia Healthy Families Survey (Survei Keluarga Sehat) of the village to inform the community about the health problems. The existed twelve indicators were obtained by researchers through Survei Keluarga Sehat which conducted by public health center (PHC) in September 2017. After the health problems confirmed, we performed the urgency, seriousness, growth (USG) analysis on the community to justify the rank of the problem priority. We led this community group to rate the urgency, seriousness, and growth of each health problem by using a 1 to 4 rating scale. The health problem with more urgent, more serious, or faster growth was rated with a higher scale. By the end of the discussion, we summed these three indicators for each problem. Problems with higher scores should be prioritized.

Second, the ranked health problems by the focus group discussion with the community were used as problem list in the focus group discussion with the health workers. The problem priority setting analysis on health workers was attended by the PHCs program coordinators, village midwives and the head of PHCs. The health workers were asked to confirm the health problems ranked by the community discussion. They were permitted to reduce or add the health problems on the list. This health problem list was then prioritized through the urgency, seriousness, growth (USG) analysis. We slightly changed the procedure of health problems prioritizing. Before we started to host the discussion, we made a combination of health problems by pairing two health problems respectively. We got sixteen combinations of health problems for comparison. Rather than asked the health workers to rate the health problems, we asked them to compare the urgency, seriousness, and growth among these combinations of health problems to make the prioritizing process sharper. A health problem which mentioned repeatedly in the comparison should be prioritized.

The results of both USG analyses were then compared to identify the differences between perceptions of the community and health workers on smoking behaviour. For the purposes of confidentiality of the health workers, the name of the village and the PHC in this study are disguised. This study has been approved by the Ethics Committee of Faculty of Public Health University of Airlangga date of the $10^{\text {th }}$ of September 2017.

\section{RESULTS}

Based on the health survey, Survei Keluarga Sehat, which conducted by PHC in September 2017, we observed the smoking behaviour of families in this cigarette-producing village. Among 251 families living in the village, $68.9 \%$ of them live with at least one family member who become active smokers. Most of these active smokers are men who ruled as the head of the household. It shows us how massive the tobacco industry influences the smoking behaviour in population. There are only $31 \%$ of families equal with 78 families who completely free of cigarette smoke. This study also identifies community and health workers perceptions toward smoking habits as a health problem. We conducted a serial focus group discussion to analyse how smoking behaviour is perceived as a health problem among community with high dependence on tobacco industry. We presented six major health problems which already identified through Indonesia Healthy Families Survey (Survei Keluarga Sehat) of the village. The community representatives confirmed the survey results as the health problems in their village. They ranked these 
six health problems based on the urgency, seriousness and growth of the health problems.

Table 1 showed six health problems that perceived by the community representatives should be considered as health problems in their village. The community prioritized the existence of mental disorders as the most prioritized health problems that should be solved first. They told that in the village there is a mental disorder patient who already discharged from psychiatric hospital and treated at home. The community representatives agree to rank this problem as the top priority since they fear that the patient will escape and harm the community. They think the mental health problem must be prioritized rather than other health problems including the smoking behaviour problems.

Among six health problems, they decided that smoking behaviour is less important than other health problems. Even though the village leaders told that an active smoker in the village can spend at least one to two packs of cigarettes in a day, the smoking problem in this village is not so serious compared to other health problems. The community representatives also think that the smoking behaviour is also not urgent to solve although they aware there is 'contagion effect' of smoking behaviour among their young generation.

The health problems resulted in the focus group discussion with the community were shared in the focus group discussion with the health workers. The focus group discussion of health workers came with conclusion to exclude three health problems and add one new health problems. The health workers removed the low coverage of breastfeeding practice, high rate of open defecation, and high prevalence of hypertension. The added the low acceptance of family planning as the health problem.

The comparison between Table 1 and Table 2 indicates that both community and health workers in cigarette-producing areas tend to judge that smoking is not a prioritized health problem in the village. Even though, perception of health workers is better than the community in prioritizing this smoking behaviour as a health problem. Both groups perceive that the high number of families with active smokers in the village is not in the top of priority to be solved.

We found that the priority on the health problems between these two groups is quite different when comparing each indicator used in priority setting. Community and health personnel have different perception in assessing the seriousness of smoking behaviour in the village. Health workers believe that smoking behaviour of community is the most serious one compared to other health problems. In contrast to health workers, community perceived that their smoking habit is not a high priority compared with other health problems. The community considers that the presence of people with mental disorders in the village is the most serious to be handled soon even though the number is small. In the other hand, health workers believe that smoking behaviour is more serious than low acceptance of family planning, but it still lacks urgency to be resolved. It indicates possibility of health workers do not focus on supporting population to quit smoking.

The health workers consider that the urgency indicator of the smoking behaviour is the lowest compared with other health problems in the village.

Table 1 Prioritized health problems based on community perceptions

\begin{tabular}{|c|c|c|c|c|c|}
\hline No. & Problems & Urgency & Seriousness & Growth & Total \\
\hline 1 & The existence of individual in population with mental disorders & 58 & 56 & 59 & 173 \\
\hline 2 & High rate of open defecation & 57 & 52 & 57 & 166 \\
\hline 3 & $\begin{array}{l}\text { Only few of population who already registered as national health } \\
\text { insurance participants }\end{array}$ & 53 & 52 & 54 & 159 \\
\hline 4 & High prevalence of hypertension & 50 & 50 & 51 & 151 \\
\hline 5 & Small number of mothers who give exclusive breastfeeding & 49 & 44 & 41 & 134 \\
\hline 6 & High number of families with active smokers & 44 & 44 & 46 & 134 \\
\hline
\end{tabular}

Table 2 Prioritized health problems based on health workers perceptions

\begin{tabular}{|c|c|c|c|c|c|}
\hline No. & Problems & Urgency & Seriousness & Growth & Total \\
\hline 1 & Low acceptance of family planning & 2 & 2 & 2 & 6 \\
\hline 2 & High number of families with active smokers & 0 & 3 & 2 & 5 \\
\hline 3 & $\begin{array}{l}\text { Only few of population who already registered as national health } \\
\text { insurance participants }\end{array}$ & 3 & 1 & 0 & 4 \\
\hline 4 & The existence of individual in population with mental disorders & 1 & 0 & 2 & 3 \\
\hline
\end{tabular}


Either do the community put smoking behaviour as the last urgent health problem that should be solve. This indicates that smoking is not considered as health problem that must be eliminated shortly. Similar perception of community and health personnel is shown in the growth indicator. Both groups perceive that the growth of smoking behaviour in the village is quite alarming. Both groups placed this problem at the middle of the list.

\section{DISCUSSION}

Smoking behaviour in the tobacco industry dependent village is apprehensive. The active smokers are generally male adults and ruled as the head of the household in this smoking-producing villages is active smokers. The fact that almost all male adults smoke makes the other who previously did not smoke became interested in smoking. ${ }^{5,9}$ Future quitting of smoking is higher in community live near people lived with disability caused by smoking behaviour. ${ }^{10}$ Our population live with high dependency toward tobacco industry which create low awareness of tobacco risks. It leads to the absence of smoking cessation.

The existence of the cigarette industry in Indonesia has always been a dilemma for the government. This industry is considered to be one of the industries that provide significant revenue for the country, even though it is argued provides losses for the country if it is linked to the health impact. Net present value (NPV) calculations of the tobacco industry proved to be detrimental to Indonesia. ${ }^{11}$ Benefits presented by the tobacco industry in increasing state revenues were smaller than the cost to be borne by the state because the population smoked. Government should be aware about alternative revenue gained by this tobacco industry rather than only giving permit for tobacco industry establishment. Increasing tobacco taxes is one of best solution to gain more income and pushing up smoking behaviour. ${ }^{12}$

In cigarette-producing areas, community is economically dependent on the tobacco industry. This study shows that the majority of villagers have high economic dependency by working on cigarette factories established in their villages. This makes the image of cigarette among community is favourable. This condition can be explained by social exchange theory. Each individual will behave in accordance with the social transactions obtained in the process.

Low socio-economic conditions are also shown to be related to smoking behaviour. Community with low socio-economic ability tend to have a higher number of active smokers population. ${ }^{5}$ By permitting tobacco industry operated in their region, local governments will earn big revenues.
The local governments will not be too concerned with cigarette control efforts. ${ }^{6}$ This will increase the number of new smokers.

There is possibility of local government which pro tobacco industry affects the perception of the health sector in the government. The results of this study prove that health workers assess the urgency of resolving the smoking behaviour in the community is not a priority, even no urgency at all to be resolved. The majority of health problems considered by health professionals in this study are health problems that clearly reveal the physical hazards presented by the problem, such as the low acceptance of family planning which leads to maternal and child health problems. Outcomes of smoking behaviour are not clearly visible and can only be seen for long periods of time so tend to be considered as low priority.

In general, health workers in this study had a better perception of the smoking dangers when compared with community. The health worker puts smoking behaviour as a second priority in health issues that must be resolved soon. Even though support from health professionals is absolutely needed to motivate smokers quit, ${ }^{13}$ health workers in this study still put smoking behaviour into a second prioritized problem that must be resolved. On the other hand, the community only puts smoking behaviour as the last health problem to be solved. This condition can occur because of the weakness of health knowledge owned by the community. A knowledge gap about the dangers of smoking can also lead to the desire to smoke. Tobacco packaging warning message is still not able to reduce the desire of individuals to try smoking. ${ }^{9}$ Education about the dangers of smoking should be more emphasis on people who have a high risk for smoking.

People in cigarette-producing areas are vulnerable to cigarette marketing. Although there is no special marketing tactic in this community, people can easily find out information about cigarettes. Public knowledge about cigarettes may be more than people's knowledge of the dangers of smoking. In the partnership of government and tobacco industry, the health sector will only receive benefit from an industry when the local government transparently explains the policy of developing an industry in the area. ${ }^{14}$ Unfortunately, policy makers are less transparent about the health effects of an industry development policy and more oriented towards economic impacts.

By living in cigarette-producing areas, people's access to cigarettes will be easier. ${ }^{6}$ Every community can have different recognition processes. Adults rely on their jobs as employees of the tobacco industry. The younger generation wants to work in the tobacco industry because it is close to where 
they live. In fact, small children are getting to know cigarettes when they know their parents every day go to work to the cigarette factory. The place-based smoking is the biggest risk that is owned by people who live in cigarette-producing areas.

Place-based smoking is a smoking behaviour of a group of populations that arise due to geographical differences. Research on place-based smoking has been widely practiced and proves the disparity of smoking behaviour in different geographies. In cigarette-producing areas the prevalence rate of smoking is very high due to the weak regulation of cigarette control carried out by the government. ${ }^{6}$ While in the families whose the members is active smokers, the prevalence of young people to quit smoking tends to remain despite health workers already gave health education. ${ }^{3}$

The stigmatization of smoking behaviour also plays a role in a population with high number of smokers. Smoking behaviour will become a culture in this community. Even today cigarette treats have become a habit in various social events such as kendurenan or religious events in the village. Population with permissive behaviour towards cigarettes, such as in this cigarette-producing areas, will produce a generation that tends to become smokers early on. Minority population that do not smoke in cigarette-producing areas tend to be different and risk being 'excluded' from the social environment. ${ }^{4}$ The risk of this community to be trapped in long time smoking behaviour is very clear based on previous study which revealed that people with smoking habit is difficult to eliminate their smoking habits. ${ }^{15}$

\section{CONCLUSION}

Smoking behaviour in cigarette-producing areas is the impact of the economic dependence created by the tobacco industry. Ease of access and weak supervision of cigarette distribution in cigarette-producing areas cause smoking behaviour to be commonplace in this community. This study has clearly shown how the perception of community and health workers in viewing smoking behaviour as a health problem. The perception of community which consider smoking as a non-serious health issue can be a latent danger in an effort to suppress the number of active smokers. Especially with the condition of health workers who assume that smoking is not an urgent problem to be addressed. Future research is expected to be able to compare between smoking behaviour of community in cigarette-producing area and non-cigarette-producing area. Social norms related to cigarettes formed in these two different groups can show how the economic dependence on tobacco industry influences the smoking behaviour of people across generations.

\section{ACKNOWLEDGEMENTS}

We gratefully acknowledge Bojonegoro Health Office for providing assistance in administrative affairs in research permit.

\section{REFERENCES}

1. Daly M, Delaney L, Baumeister RF. Self-control, future orientation, smoking, and the impact of Dutch tobacco control measures. Addictive Behaviors Reports. 2015;1:89-96.

2. Weitkunat R, Lee PN, Baker G, Sponsiello-Wang Z, González-Zuloeta Ladd AM, Lüdicke F. A novel approach to assess the population health impact of introducing a modified risk tobacco product. Regulatory Toxicology and Pharmacology. 2015;72(1):87-93.

3. English LML, Hsia J, Malarcher A. Tobacco advertising, promotion, and sponsorship (TAPS) exposure, anti-TAPS policies, and students' smoking behavior in Botswana and South Africa. Preventive Medicine (Baltim). 2016;91:S28-34.

4. Glenn NM, Lapalme J, McCready G, Frohlich KL. Young adults' experiences of neighbourhood smoking-related norms and practices: A qualitative study exploring placebased social inequalities in smoking. Social Science of Medicine. 2017;189:17-24.

5. Zhang $\mathrm{D}, \mathrm{Hu} \mathrm{Z}$, Orton S. Socio-economic and psychosocial determinants of smoking and passive smoking in older adults. Biomedical and Environmental Sciences. 2013;26(6):453-67.

6. Yang T, Barnett R, Rockett IRH, Yang XY, Wu D, Zheng $\mathrm{W}$, et al. The impact of regional economic reliance on the tobacco industry on current smoking in China. Health and Place. 2015;33:159-171.

7. Indonesia Ministry of Health. Laporan Nasional Riskesdas 2018 [National Report of The 2018 Basic Health Research]. Jakarta: Indonesia Ministry of Health; 2018.

8. Ribisl KM, D'Angelo H, Feld AL, Schleicher NC, Golden SD, Luke DA, et al. Disparities in tobacco marketing and product availability at the point of sale: Results of a national study. Preventive Medicine (Baltim). 2017;105:381-8.

9. Elton-Marshall T, Wijesingha R, Kennedy RD, Hammond D. Disparities in knowledge about the health effects of smoking among adolescents following the release of new pictorial health warning labels. Preventive Medicine (Baltim). 2018;111:358-365.

10. Lin W, Sloan F. Risk perceptions and smoking decisions of adult Chinese men. Journal of Health Economics. 2015;39:60-73.

11. Likke, Llewelyn R, Musianto L. Analisis cost-benefit terhadap industri rokok di Indonesia [Cost-benefit analysis of tobacco industry in Indonesia]. Jurnal Manajemen \& Kewirausahaan. 2000;2(2):68-85.

12. Salti N, Brouwer E. The health, financial and distributional consequences of increases in the tobacco excise tax among smokers in Lebanon. Social Science \& Medicine. 2016;170:161-169.

13. Gentry S, Craig J, Holland R, Notley C. Smoking cessation for substance misusers: A systematic review of qualitative studies on participant and provider beliefs and perceptions. Drug and Alcohol Dependence. 2017;180:178-192.

14. Jarman H. Trade policy governance: What health policymakers and advocates need to know. Health Policy. 2017;121(11):1105-12.

15. Rosita R, Suswardany DL, Abidin Z. Penentu keberhasilan berhenti merokok pada mahasiswa [Determinants of the success on quitting smoking among university students]. Jurnal Kesehatan Masyarakat. 2012;8(1):1-9.

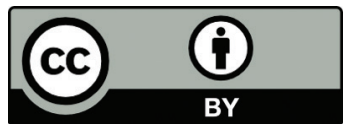

This work is licensed under a Creative Commons Attribution 